\title{
PROFILE OF TOLL-LIKE RECEPTOR mRNA EXPRESSION IN THE CHOROID PLEXUS IN ADULT EWES
}

\author{
Janina SKIPOR $^{1 *}$, Aleksandra SzCZEPKOWSKA ${ }^{1}$, Marta KowALEWSKA ${ }^{1}$, \\ Andrzej P. HERMAN ${ }^{2}$ and Paweł LISIEWSKI ${ }^{1}$ \\ ${ }^{1}$ Institute of Animal Reproduction and Food Research, Polish Academy of Sciences, \\ ul. Tuwima 10, 10-748 Olsztyn, Poland; ${ }^{2}$ Department of Endocrinology, \\ The Kielanowski Institute of Animal Physiology and Nutrition, \\ Polish Academy of Sciences, Jablonna n/Warsaw, Poland
}

(Received 28 January 2014; accepted 25 June 2014)

The blood-cerebrospinal fluid barrier (BCSFB) located in the epithelial cells of the choroid plexus (CP) forms the interface between the cerebrospinal fluid (CSF) and pathogen components circulating in the blood. The CP is also implicated in the passage of peripheral immune signals and circulation of immune cells into the central nervous system. Toll-like receptors (TLRs) are patternrecognition receptors that play a crucial role in the recognition of pathogens and triggering of the innate immune response. In sheep, ten members of the TLR family have been identified and cloned. We used real-time PCR analyses to examine the profiles of TLR mRNA expression in the CP of cerebral ventricles in healthy adult ewes. The transcripts for all ten TLRs except TLR8 were present; however, we observed a high variation in the degree of expression of the TLR5 and TLR1 genes (coefficient of variation: $61 \%$ and $46 \%$, respectively) as well as a moderate variation in the expression of the TLR4 (34\%), TLR2 (27\%) and TLR6 (26\%) genes. The TLR9, TLR7, TLR3 and TLR10 genes were the four receptors with relatively invariable expression levels (coefficient of variation: $7 \%, 8 \%, 16 \%$ and $17 \%$, respectively) across the six adult ewes. The concentration of cortisol in blood collected prior to sacrificing the ewes ranged from 0.18 to $78.9 \mathrm{ng} / \mathrm{ml}$. There was no correlation between cortisol concentration and mRNA expression of any of the examined TLRs. These data suggest that the CP has the potential to sense the presence of many bacterial and viral components and mediate responses for the elimination of invading microorganisms, thereby protecting the brain.

Key words: Toll-like receptors, choroid plexus, ewe

The immune system plays an important role in the protection of an organism against pathogenic invasion through contact, ingestion and inhalation. The first defensive line, which is activated immediately after infection, is natural (innate) immunity. The recognition of particular types of molecules that are com-

*Corresponding author; E-mail: j.skipor@pan.olsztyn.pl; Phone: 0048 (89) 5393-126; Fax: 0048 (89) 5357-421 
mon to many pathogens (called pathogen-associated molecular patterns, PAMPs) plays a key role in the initiation of the innate immune response (Medzhitov and Janeway, 1998). PAMPs are recognised by pattern recognition receptors, among them toll-like receptors (TLR), which are expressed by many cell types such as neutrophils, macrophages, endothelial and epithelial cells, natural killer cells and dendritic cells (Werling and Coffey, 2007). Mammalian TLRs comprise a large family consisting of at least 13 members; all TLRs have been identified in mice and 10 (TLR1-10) have been identified in humans, pigs, cattle and sheep (Takeda and Akira, 2005; Chang et al., 2009). Individual TLRs detect specific microbial components derived from pathogens such as bacteria, fungi, protozoa and viruses (Takeda and Akira, 2005). TLR2 binds to a variety of microbial components, which include: lipoproteins/lipopeptides, peptidoglycans and lipoteichoic acid, lipoarabinomannan, glycoinositolphospholipids, a phenol-soluble maudlin, zymosan, glycolipids and atypical lipopolysaccharides (LPS) found in Leptospira interrogans and Porphyromonas gingivalis. The wide spectrum of microbial components recognised by TLR2 is the result of heterodimerisation of TLR2 with TLR1 and TLR6, which discriminates between diacyl and triacyl lipopeptides. TLR3 is implicated in the detection of double-stranded RNA and viruses (Tabeta et al., 2004). TLR4 is known as a receptor for LPS and endogenous ligands (such as heat shock proteins and other proteins) involved in the inflammatory response even in the absence of infection. TLR5 recognises flagellin, a monomeric constituent of bacterial flagella, while TLR7 and TLR8 detect singlestranded RNA from viruses such as human immunodeficiency virus, vesicular stomatitis virus and influenza virus (Takeda and Akira, 2005). TLR9 appears to be a receptor for viral-derived CpG DNA because TLR9-mutant mice are susceptible to mouse cytomegalovirus infection (Takeda and Akira, 2005). TLR10 is an orphan member of the TLR family (Hasan et al., 2005).

Following tissue damage, TLRs may also detect certain host proteins, such as beta-defensins, and heat shock proteins (Hopkins and Sriskandan, 2005). The stimulation of TLRs by their respective ligands triggers the expression of several genes that are involved in the synthesis of chemokines and cytokines, as well as adhesive and co-stimulatory molecules (Takeda et al., 2003). It has been demonstrated that peripheral inflammation can stimulate the synthesis of inflammatory cytokines in the brain (Laye et al., 1994; Pitossi et al., 1997). In general, the brain is protected from pathogens through brain barriers. Two barrier layers limit and regulate the exchange of molecules at the interface between the blood and brain tissue and their fluid spaces: the blood-brain barrier (BBB), located between the blood and interstitial fluid surrounding the neural tissue, and the blood-cerebrospinal fluid (CSF) barrier (BCSFB), which consists of the internally situated choroid plexus (CP) and the externally located arachnoid membrane (Skipor and Thiery, 2008). The cellular basis of these barriers is located within the endothelial cells of the microvessels of the brain and the epithelial 
cells of the CP and arachnoid barrier cells (Skipor and Thiery, 2008). Some ligands of TLRs, such as LPS and poly I:C (TLR3 ligand), do not pass brain barriers; therefore, the localisation of TLRs in structures where these barriers are localised plays a key role in transferring signals from TLRs to the brain (Singh and Jiang, 2004; Borghetti et al., 2009). Laflamme and Rivest (2001) used in situ hybridisation techniques to provide evidence that the mRNA for TLR4 is present in the circumventricular organs, $\mathrm{CP}$ and leptomeninges. These structures are easily reached by molecules present in the bloodstream; therefore, they are exposed to pathogens and the molecules derived from them early in systemic infection (Mishra et al., 2006).

The profile of TLR expression in the brain barrier of domestic animals is not known. Therefore, the aim of this study was to evaluate the profile of TLR mRNA expression in the CP of adult ewes. The ovine model is commonly used and is becoming more widely accepted as an animal model for neuroendocrine studies in domesticated animals.

\section{Materials and methods}

\section{Animals and treatment}

The study was performed on adult ewes of the Polish Black Face breed $(\mathrm{n}=6$, body mass: $50-60 \mathrm{~kg})$. Animals were kept indoors under natural lighting conditions (latitude $52^{\circ} \mathrm{N}, 21^{\circ} \mathrm{E}$ ) and fed a constant diet of hay, straw and commercial concentrates. Water and mineral licks were available ad libitum. Blood samples $(5 \mathrm{ml})$ were collected in late June through a jugular venipuncture site. After centrifugation in heparinised tubes, plasma was stored at $-20{ }^{\circ} \mathrm{C}$ until assayed. Thereafter, animals were sacrificed in a certified slaughterhouse. After decapitation, the brain was dissected and the $\mathrm{CP}$ was detached from its anchor to Galen's vein and then split along the midline, separating the $\mathrm{CP}$ from each lateral ventricle. Both sections of the $\mathrm{CP}$ were separately frozen in liquid nitrogen and stored at $-80^{\circ} \mathrm{C}$ until further analysis. All animal procedures were conducted in accordance with the Polish Guide for the Care and Use of Animals (1997) and approved by the Local Ethics Committee (authorisation no. 26/2012).

\section{Measurement of cortisol in the blood plasma}

The concentration of cortisol in the blood plasma was assayed using a competitive electrochemiluminescence immunoassay (ECLIA, Roche) in accordance with manufacturer's protocol. This analysis was performed by our accredited Analytical Laboratory. 


\section{Relative gene expression assays}

One section of the $\mathrm{CP}$ from each animal was cut into smaller pieces and $20 \mathrm{mg}$ of frozen tissue was used for total RNA isolation. Initial homogenisation of the frozen CP tissue was performed in Lysing Matrix D (MP Biomedicals) and filled with lysing buffer from NucleoSpinRNA (RA1) using a FastPrep24 instrument (MP Biomedicals) at an oscillation speed of $6.5 \mathrm{~m} / \mathrm{s}$ for $30 \mathrm{~s}$. Total RNA was isolated using a NucleoSpin RNAII assay (Marcherey-Nagel) according to the manufacturer's protocol. The genomic DNA digestion step was included in the isolation procedure. The purity and concentration of isolated RNA were quantified by spectrophotometry, measuring the optical density at 260 and $280 \mathrm{~nm}$, using a NanoDrop 1000 instrument (Thermo Scientific). The integrity of RNA was verified by electrophoresis using $1.2 \%$ agarose gel stained with ethidium bromide (Sigma Aldrich).

One microgram of total RNA was retained for further use in the reverse transcription (RT) reaction. The RT reaction was performed with a DyNAmo cDNA Synthesis Kit (Thermo Scientific) according to the protocol supplied by the manufacturer. The resulting cDNA was stored at $-20^{\circ} \mathrm{C}$ until further analysis.

The expression pattern of the TLRs in the ovine CP was determined by real-time PCR. Specific primer pairs for all of the analysed genes were used according to the literature (see Table 1). All primers were synthesised by Genomed (Poland). To find the optimal temperature for annealing the primers, gradient PCR reactions were performed with a SensoQuest Labcycler (SensoQuest GmbH), using the RedTaq Ready Mix (Sigma Aldrich). The following protocol was used: $95^{\circ} \mathrm{C}$ for $5 \mathrm{~min}$ for the hot start REDTaq DNA polymerase, followed by $40 \mathrm{cy}-$ cles of $94{ }^{\circ} \mathrm{C}$ for $30 \mathrm{~s}$ (denaturation), then $\mathrm{X}{ }^{\circ} \mathrm{C}\left(54.9^{\circ} \mathrm{C} / 56.4{ }^{\circ} \mathrm{C} / 57.8^{\circ} \mathrm{C} /\right.$ $59.3{ }^{\circ} \mathrm{C} / 60.7^{\circ} \mathrm{C} / 62.2^{\circ} \mathrm{C}$ ) for $45 \mathrm{~s}$ (annealing), then $72{ }^{\circ} \mathrm{C}$ for $30 \mathrm{~s}$ (extension) and finally $72{ }^{\circ} \mathrm{C}$ for $5 \mathrm{~min}$ (last chain elongation). After gradient PCR, the products were separated in $2 \%$ agarose gels, stained with ethidium bromide and examined under UV light (Gel Logic 100; KODAK).

Real-time PCR analyses were performed on a Viia7 instrument (Applied Biosystems). Each real-time PCR reaction $(10 \mu \mathrm{l})$ contained $3 \mu \mathrm{l}$ of diluted (1:10) cDNA, $0.2 \mu \mathrm{M}$ each of forward and reverse primers and $5 \mu 1$ of DyNAmo SYBR Green qPCR Kit with ROX (Thermo Scientific). The following protocol was used: $95^{\circ} \mathrm{C}$ for $10 \mathrm{~min}$ for the hot start modified Tbr DNA polymerase, followed by 40 cycles of $95^{\circ} \mathrm{C}$ for $15 \mathrm{~s}$ (denaturation), $\mathrm{X}^{\circ} \mathrm{C}$ (see Table 1) for $30 \mathrm{~s}$ (annealing) and $72{ }^{\circ} \mathrm{C}$ for $30 \mathrm{~s}$ (extension). The last cycle was performed to evaluate the specific amplification using a final melting curve analysis under continuous fluorescence measurement. The results were analysed using the realtime PCR Miner (available online: http://www.miner.ewindup.info/version2), which is based on the algorithm developed by Zhao and Fernald (2005). 
Table 1

Sequences of oligonucleotide primers used for real-time PCR

\begin{tabular}{|c|c|c|c|c|}
\hline Gene & Primers $\left(5^{\prime} \rightarrow 3^{\prime}\right)$ & $\begin{array}{l}\text { Product } \\
\text { size (bp) }\end{array}$ & Reference & $\begin{array}{c}\text { Temperature of } \\
\text { primers annealing }\left({ }^{\circ} \mathrm{C}\right)\end{array}$ \\
\hline TLR1 & $\begin{array}{l}\text { Forward: CCCACAGGAAAGAAATTCCA } \\
\text { Reverse: GGAGGATCGTGATGAAGGAA }\end{array}$ & 208 & Menzies and Ingham (2006) & 55 \\
\hline TLR2 & $\begin{array}{l}\text { Forward: GGCTGTAATCAGCGTGTTCA } \\
\text { Reverse: GATCTCGTTGTCGGACAGGT }\end{array}$ & 159 & Chang et al. (2009) & 55 \\
\hline TLR3 & $\begin{array}{l}\text { Forward: TCAGCTCCAACTGGAGAACC } \\
\text { Reverse: CACCCAGGAGAGAACTCTTTGA }\end{array}$ & 150 & Chang et al. (2009) & 59 \\
\hline TLR5 & $\begin{array}{l}\text { Forward: CGACAACCTCCAAGTTCTCAA } \\
\text { Reverse: TTTCCCCAGGAATTTGAATG }\end{array}$ & 152 & Chang et al. (2009) & 55 \\
\hline TLR6 & $\begin{array}{l}\text { Forward: TTTGTCCTCAGGAACCAAGC } \\
\text { Reverse: TCATATTCCAAAGAATTCCAGCTA }\end{array}$ & 213 & Chang et al. (2009) & 55 \\
\hline TLR9 & $\begin{array}{l}\text { Forward: CCCTGGAGAAGCTGGACAT } \\
\text { Reverse: GACAGGTCCACGAAGAGCAG }\end{array}$ & 175 & Chang et al. (2009) & 59 \\
\hline TLR10 & $\begin{array}{l}\text { Forward: TGCCAAGACATCCATTCTGT } \\
\text { Reverse: GAATTGTGGTCAAGATAAACCTTAC }\end{array}$ & 149 & Chang et al. (2009) & 55 \\
\hline GAPDH & $\begin{array}{l}\text { Forward: TGACCCCTTCATTGACCTTC } \\
\text { Reverse: GATCTCGCTCCTGGAAGATG }\end{array}$ & 143 & Herman and Tomaszewska-Zaremba (2010) & $55 / 59^{*}$ \\
\hline
\end{tabular}

TLR: Toll-like receptor; GAPDH: glyceraldehyde-3-phosphate dehydrogenase; ${ }^{*}$ the gradient PCR analysis for GAPDH showed similar results at all annealing temperatures 


\section{Data analysis}

The concentration of cortisol is presented as the mean \pm standard deviation (SD). Real-time PCR results are presented as the relative gene expression (mean \pm standard error of the mean [SEM]) of the TLR genes vs. the reference gene (GAPDH). The significance of differences between the expression of each TLR gene was analysed using a one-way analysis of variance (ANOVA) with multiple comparison Tukey's post-hoc tests. Statistical significance was set at $\mathrm{P}<0.05$. Statistical analyses were performed using GraphPad PRISM 6 (San Diego, USA), including calculations of the coefficient of variation for the expression values of each TLR gene and the correlations between cortisol concentration and the gene expression of each TLR.

\section{Results}

Mean ( \pm SEM) expression of each TLR, determined by real-time PCR, in the ovine CP is presented in Fig. 1. Transcripts for all TLR genes, except TLR8, were found in all of the ewes examined. Real-time PCR showed that TLR3 and TLR7 had the highest expression, followed by TLRs 6, 5, 9, 2, 4, 1 and 10, which had the lowest expression observed in this study. A high variation in the degree of expression of TLR5 and TLR1 genes was observed (coefficient of variation $61 \%$ and $46 \%$, respectively); however, this high variability was not found in TLR9 (7\%), TLR7 (8\%), TLR3 (16\%) and TLR10 (17\%). For TLRs 6, 2 and 4 , the coefficient of variation was calculated as $26 \%, 27 \%$, and $34 \%$, respectively (Fig. 1). The concentration of cortisol in the blood plasma collected just before ewes were sacrificed ranged from 0.18 to $78.9 \mathrm{ng} / \mathrm{ml}$. There was no correlation between the cortisol concentration and the mRNA expression of any of the TLRs examined.

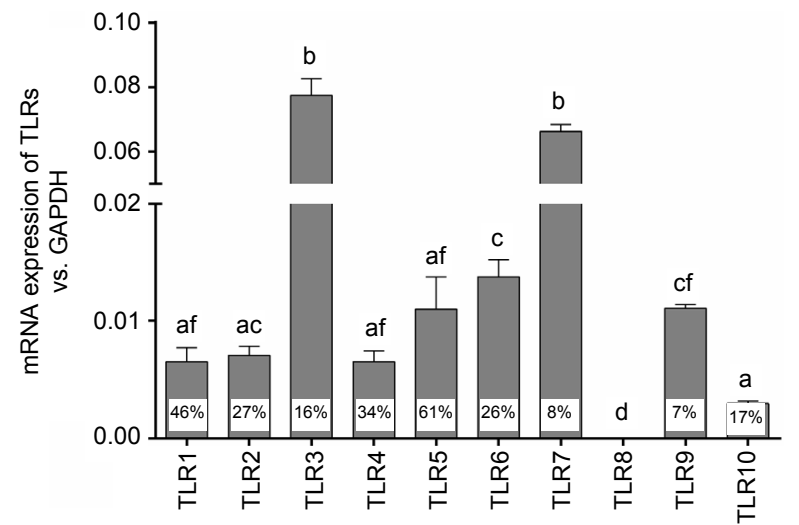

Fig. 1. TLRs relative mRNA expression (mean \pm SEM) vs. GAPDH in the choroid plexus of cerebral ventricles of adult ewes $(n=6)$. The coefficient of variations $(\%)$ for each TLR is inserted into each bar. Differences between means marked with different letters are statistically significant $(\mathrm{P}<0.05)$ 


\section{Discussion}

In the present study, we examined the profiles of mRNA expression of TLRs in the CP of adult ewes. Transcripts for nine TLRs were present; however, individual TLRs were differentially expressed. This differential expression potentially allows for the detection of many bacterial and viral components, mediating the responses necessary for the elimination of invading microorganisms, thereby protecting the brain. However, there are also data that demonstrate that infectious and non-infectious endogenous stimuli may be associated with a disturbance of BCSFB function (Marques et al., 2009a, $b$; Schwerk et al., 2010; Stridh et al., 2013). Marques et al. (2009a, b) showed an altered gene expression profile in the CP of mice after peripheral administration of LPS, including the up-regulation of genes implicated in acute phase reactions and extracellular matrix remodelling, as well as the down-regulation of genes involved in the maintenance of BCSFB function. LPS rapidly induce the mRNA levels of interleukin 1 beta (IL-1 $\beta$ ) and tumour necrosis factor alpha (TNF $\alpha$ ) in the CP as well as TNF $\alpha$ concentration in the CSF of mice (Marques et al., 2007). Moreover, activation of TLR1/TLR2 and TLR4 in mice was shown to down-regulate mRNA expression of the tight junction protein occludin in the CP, leading to increased BCSFB penetration by blood white cells (Stridh et al., 2013). All of these findings, taken together, may explain the rapid increase in IL-1 $\beta$ concentration observed in the CSF of adult ewes treated with LPS (data not published). In ewes, IL-1 $\beta$ infused into the brain ventricles reduces GnRH biosynthesis and release during an immune/inflammatory challenge (Herman et al., 2012). This is particularly interesting because, in animals, bacterial and viral infections induce a strong immune response that affects the animal's productivity, including reproduction. Decreased concentrations of luteinising hormone following LPS administration has been documented in cows, sheep and pigs (Tomaszewska-Zaremba and Herman, 2009). Moreover, pro-inflammatory cytokines appear to be important immune mediators involved in the central inhibition of the neuroendocrine reproductive axis (Tomaszewska-Zaremba and Herman, 2009).

Among the TLRs expressed in the CP, TLR3, TLR7, TLR9 and TLR10 presented relatively invariant expression levels across all ewes investigated. The reason for the high variability found in the mRNA expression of TLR1 and TLR5 in our studies is not known. It has been previously demonstrated that neuroendocrine hormones, particularly glucocorticoids, play a role in modulating TLR expression (Shuto et al., 2002). However, in this study we could exclude the involvement of glucocorticoids in the induction of variability, which was found in the mRNA expression of TLR1 and TLR5, because no correlations were found between cortisol concentration and the mRNA expression of each TLR. Constitutive expression of mRNA has been demonstrated so far for TLR1, TLR2, TLR3 and TLR4 in the CP of neonatal mice (Stridh et al., 2013), TLR2 (Laflamme et 
al., 2001) and TLR4 in adult mice (Chakravarty and Herkenham, 2005) and TLR4 in adult rats (Laflamme and Rivest, 2001). It should be noted that, in the present studies, mRNA was extracted from the whole CP including endothelial, epithelial and blood cells, as well as macrophages and dendritic cells residing in the stromal matrix (Meeker et al., 2012). Therefore, TLR transcripts found in the $\mathrm{CP}$ may originate from all of these components. To our knowledge, there are no studies showing the pattern of TLR expression separately in epithelial, endothelial and other cells of the CP. However, there are studies demonstrating that the Gram-positive bacterium Streptococcus suis and LPS induce the expression of cytokines in porcine CP epithelial cells (Schwerk et al., 2011). TLR2, TLR6 and TLR9 are involved in the recognition of Streptococcus suis (Zheng et al., 2012). Therefore, TLR2, TLR4, TLR6 and TLR9 are at least expressed in the epithelial cells of the porcine CP. It should be noted that the pattern of TLR expression has been presented for the human brain endothelial cell line (hCMEC/D3) and primary cultures of rat brain endothelial cells. The hCMEC/D3 cells express TLR2, TLR3, TLR4 and TLR6, whereas in endothelial cells of the rat brain, TLR4 was undetected (Nagyoszi et al., 2010).

According to Nalubamba et al. $(2007,2013)$, individual TLRs are differentially expressed in ovine tissues such as the spleen, lung, kidney, skin and urinary bladder. In all of the investigated tissues, TLR4 was expressed at the highest transcript level, while TLR9 and TLR10 were expressed at the lowest level, except in the spleen and lungs. Our studies showed that, in the ovine CP, TLR3 and TLR7 were expressed at the highest level. Expression of TLR1, TLR2 and TLR6 in the ovine CP allow for the formation of heterodimers between TLR2 and TLR1 and TLR6. Our findings indicate the mRNA expression of nine members of the TLR family in the CP of adult ewes; however, further studies are necessary to examine the protein profiles of TLRs. A study conducted by Mishra et al. (2006) demonstrated that not all TLRs, for which mRNA is found, are expressed as proteins. For example, ependymal cells in mice were detected as being positive for TLR2, TLR6 and TLR7 proteins, suggesting that other TLRs may be posttranscriptionally regulated (Mishra et al., 2006). However, it has also been suggested in previous studies that the protein expression of TLRs in the brain is variable due to the lack of high specificity of the antibodies used (Mallard, 2012).

\section{Acknowledgements}

This work was supported by a project funded by the National Science Centre, allocated on the basis of decision-DEC 2011/03/B/NZ9/00118, and by the Ministry of Science and Higher Education, Warsaw, Poland. 


\section{References}

Borghetti, P., Saleri, R., Mocchegiani, E., Corradi, A. and Martelli, P. (2009): Infection, immunity and the neuroendocrine response. Vet. Immunol. Immunopathol. 130, 141-162.

Chakravarty, S. and Herkenham, M. (2005): Toll-like receptor 4 on nonhematopoietic cells sustains CNS inflammation during endotoxemia, independent of systemic cytokines. J. Neurosci. 25, 1788-1796.

Chang, J. S., Russell, G. C., Jann, O., Glass, E. J., Werling, D. and Haig, D. M. (2009): Molecular cloning and characterization of Toll-like receptors 1-10 in sheep. Vet. Immunol. Immunopathol. 127, 94-105.

Hasan, U., Chaffois, C., Gaillard, C., Saulnier, V., Merck, E., Tancredi, S., Guiet, C., Brière, F., Vlach, J., Lebecque, S., Trinchieri, G. and Bates, E. E. M. (2005): Human TLR10 is a functional receptor expressed by B cells and plasmacytoid dendritic cells, which activates gene transcription through MyD88. J. Immunol. 174, 2942-2950.

Herman, A. P. and Tomaszewska-Zaremba, D. (2010): Effect of endotoxin on the expression of GnRH and GnRHR genes in the hypothalamus and anterior pituitary gland of anestrous ewes. Anim. Reprod. Sci. 120, 105-111.

Herman, A. P., Misztal, T., Romanowicz, K. and Tomaszewska-Zaremba, D. (2012): Central injection of exogenous IL-1 $\beta$ in the control activities of hypothalamic-pituitary-gonadal axis in anestrous ewes. Reprod. Dom. Anim. 47, 44-52.

Hopkins, P. A. and Sriskandan, S. (2005): Mammalian Toll-like receptors: to immunity and beyond. Clin. Exp. Immunol. 140, 395-407.

Laflamme, N. and Rivest, S. (2001): Toll-like receptor 4: the missing link of the cerebral innate immune response triggered by circulating gram-negative bacterial cell wall components. FASEB J. 15, 155-163.

Laflamme, N., Soucy, G. and Rivest, S. (2001): Circulating cell wall components derived from gram-negative, not Gram-positive, bacteria cause a profound induction of the geneencoding Toll-like receptor 2 in the CNS. J. Neurochem. 79, 648-657.

Laye, S., Parnet, P., Goujon, E. and Dantzer, R. (1994): Peripheral administration of lipopolysaccharide induces the expression of cytokine transcripts in the brain and pituitary of mice. Brain Res. Mol. Brain Res. 27, 157-162.

Mallard, C. (2012): Innate immune regulation by Toll-like receptors in the brain. ISRN Neurol. doi: $10.5402 / 2012 / 701950$.

Marques, F., Sousa, J. C., Coppola, G., Falcao, A. M., Rodrigues, A. J., Geschwind, D. H., Sousa, N., Correia-Neves, M. and Palha, J. A. (2009a): Kinetic profile of the transcriptome changes induced in the choroid plexus by peripheral inflammation. J. Cer. Blood Flow Metab. 29, 921-932.

Marques, F., Sousa, J. C., Coppola, G., Geschwind, D. H., Sousa, N., Palha, J. A. and CorreiaNeves, M. (2009b): The choroid plexus response to a repeated peripheral inflammatory stimulus. BMC Neurosci. doi:10.1186/1471-2202-10-135.

Marques, F., Sousa, J. C., Correia-Neves, M., Oliveira, P., Sousa, N. and Palha, J. A. (2007): The choroid plexus response to peripheral inflammatory stimulus. Neuroscience 144, 424-430.

Medzhitov, R. and Janeway, C. A. J. (1998): Innate immune recognition and control of adaptive immune responses. Semin. Immunol. 10, 351-353.

Meeker, R. B., Williams, K., Killebrew, D. A. and Hudson, L. C. (2012): Cell trafficking through the choroid plexus. Cell Adh. Migr. 6, 390-396.

Menzies, M. and Ingham, A. (2006): Identification and expression of Toll-like receptors 1-10 in selected bovine and ovine tissues. Vet. Immunol. Immunopathol. 109, 23-30.

Mishra, B. B., Mishra, P. K. and Teale, J. M. (2006): Expression and distribution of Toll-like receptors in the brain during murine neurocysticercosis. J. Neuroimmunol. 181, 46-56. 
Nagyoszi, P., Wilhelm, I., Farkas, A. E., Fazakas, C., Dung, N. T., Haskó, J. and Krizbai, I. A. (2010): Expression and regulation of Toll-like receptors in cerebral endothelial cells. Neurochem. Int. 57, 556-564.

Nalubamba, K. S., Gossner, A. G., Dalziel, R. G. and Hopkins, J. (2007): Differential expression of pattern recognition receptors in sheep tissues and leukocyte subsets. Vet. Immunol. Immunopathol. 118, 252-262.

Nalubamba, K. S., Gossner, A. G., Dalziel, R. G. and Hopkins, J. (2013): Corrigendum to 'Differential expression of pattern recognition receptors in sheep tissues and leukocyte subsets'. Vet. Immunol. Immunopathol. 153, 175-176.

Pitossi, F., del Rey, A., Kabiersch, A. and Besedovsky, H. (1997): Induction of cytokine transcripts in the central nervous system and pituitary following peripheral administration of endotoxin to mice. J. Neurosci. Res. 48, 287-298.

Schwerk, C., Adam, R., Borkowski, J., Schneider, H., Klenk, M., Zink, S., Quednau, N., Schmidt, N., Stump, C., Sagar, A., Spellerberg, B., Tenenbaum, T., Koczan, D., Klein-Hitpass, L. and Schroten, H. (2011): In vitro transcriptome analysis of porcine choroid plexus epithelial cells in response to Streptococcus suis: release of pro-inflammatory cytokines and chemokines. Microbes. Infect. 13, 953-962.

Schwerk, C., Rybarczyk, K., Essmann, F., Seibt, A., Molleken, M. L., Zeni, P., Schroten, H. and Tenenbaum, T. (2010): TNF $\alpha$ induces choroid plexus epithelial cell barrier alterations by apoptotic and nonapoptotic mechanisms. J. Biomed. Biotech. doi:10.1155/2010/307231.

Shuto, T., Imasato, A., Jono, H., Sakai, A., Xu, H., Watanabe, T., Rixter, D. D., Kai, H., Andalibi, A., Linthicum, F., Guan, Y. L., Han, J., Cato, A. C., Lim, D. J., Akira, S. and Li, J. D. (2002): Glucocorticoids synergistically enhance nontypeable Haemophilus influenzainduced Toll-like receptor 2 expression via a negative cross-talk with p38 MAP kinase. J. Biol. Chem. 277, 17263-17270.

Singh, A. K. and Jiang, Y. (2004): How does peripheral lipopolysaccharide induce gene expression in the brain of rats? Toxicology 201, 197-207.

Skipor, J. and Thiery, J. C. (2008): The choroid plexus-cerebrospinal fluid system: undervaluated pathway of neuroendocrine signaling into the brain. Acta Neurobiol. Exp. 68, 417-429.

Stridh, L., Ek, C. J., Wang, X., Nilsson, H. and Mallard, C. (2013): Regulation of Toll-like receptors in the choroid plexus in the immature brain after systemic inflammatory stimuli. Transl. Stroke Res. 4, 220-227.

Tabeta, K., Georgel, P., Janssen, E., Du, X., Hoebe, K., Crozat, K., Mudd, S., Shamel, L., Sovath, S., Goode, J., Alexopoulou, L., Flavell, R. A. and Beutler, B. (2004): Toll-like receptors 9 and 3 as essential components of innate immune defense against mouse cytomegalovirus infection. Proc. Natl Acad. Sci. USA 101, 3516-3521.

Takeda, K. and Akira, S. (2005): Toll-like receptors in innate immunity. Int. Immunol. 17, 1-14.

Takeda, K., Kaisho, T. and Akira, S. (2003): Toll-like receptors. Annu. Rev. Immunol. 21, 335-376.

Tomaszewska-Zaremba, D. and Herman, A. (2009): The role of immunological system in the regulation of gonadoliberin and gonadotropin secretion. Reprod. Biol. 9, 11-23.

Werling, D. and Coffey, T. C. (2007): Pattern recognition receptors in companion and farm animals - The key to unlocking the door to animal disease? Vet. J. 174, 240-251.

Zhao, S. and Fernald, R. D. (2005): Comprehensive algorithm for quantitative real-time polymerase chain reaction. J. Comput. Biol. 12, 1047-1064.

Zheng, H., Luo, X., Segura, M., Sun, H., Ye, C., Gottschalk, M. and Xu, J. (2012): The role of Toll-like receptors in the pathogenesis of Streptococcus suis. Vet. Microbiol. 156, 147-156. 